\title{
Impact of Bacterial Biofilm in Veterinary Medicine: An Overview
}

\author{
S. Chakraborty ${ }^{1 *}$, T.K. Dutta ${ }^{1}$ A. De ${ }^{2}$, M. Das ${ }^{3}$ and S. Ghosh ${ }^{4}$ \\ ${ }^{1}$ Department of Veterinary Microbiology, ${ }^{3}$ Department of Veterinary Public Health and \\ Epidemiology, ${ }^{4}$ Department of Veterinary Parasitology, \\ Central Agricultural University-Imphal, Selesih, Aizawl, Mizoram - 796014, India \\ ${ }^{2}$ Department of Veterinary Physiology and Biochemistry, CVSc \& AH, R. K. Nagar, West \\ Tripura - 799088, India \\ *Corresponding author
}

A B S T R A C T

\section{Keywords}

Biofilm, Antibiotic resistance,

Veterinary, Infection, Zoonotic

Article Info

Accepted:

26 March 2018

Available Online:

10 April 2018
Biofilms are communities of microorganisms that are attached to a surface and play a significant role in the persistence of bacterial infections. Biofilm bacteria are highly resistant to antimicrobial agents and host immune responses resulting in chronic infection. There is paucity of information regarding biofilm bacteria of veterinary importance and their role in disease pathogenesis. Biofilm associated infection can cause huge economic loss in livestock industries in terms of production. For example, chronic mastitis due to biofilm producing Staphylococcus aureus and Streptococcus spp. is almost incurable with common antibiotics. Moreover, biofilm bacteria are potential zoonotic agents. So we should ventured alternative managemental practices to fight against biofilm bacteria.

\section{Introduction}

Since their birth, bacteria are constantly modified and adopted themselves to combat all the hostile environment of planet. As a result, for self-defense, multidrug-resistant (MDR) and extremely resistant (XDR) bacteria emerged throughout the world pose a threat to global health. The situation of antibiotic resistance is increased up to 1000 times if the infections are associated with biofilm producing bacteria compared to their planktonic counterparts (Rasmussen and Givskov, 2006). Biofilm is a well-organized, cooperating community of microorganisms embedded in self producing extracellular polymeric substance (EPS). Biofilm associated cell is differentiated from 
suspended counterparts by reduced growth rate, up and down regulation of gene and generation of extracellular polymeric matrix (Kokare et al., 2009). The high resistance to harsh conditions, including pollutants (Joubert et al., 2006), desiccation (Queck et al., 2006), protozoan grazing, antimicrobial agents in nature and host defences (Taylor and Webster 2009) in chronic infections, is some/one of the most important features of biofilms. It is estimated that $99 \%$ of bacteria in nature exist in biofilms, while biofilms account for more than $65 \%$ of nosocomial infections (Böhme et al., 2009) and approximately $61 \%$ zoonotic human infection (Garcia and Percival, 2011). Biofilm bacteria are also involved for many diseases in veterinary medicine including pneumonia, liver abscesses, enteritis, wound infections and mastitis infections (Olson et al., 2002; Clutterbuck et al., 2007). In this overview, emphasis has given on biofilm architecture, mechanism of biofilm formation, status of biofilm associated diseases in animal, zoonotic importance, probable reason for antibiotic resistance, possible diagnostic approaches and control strategies.

\section{Structure of biofilm}

The structure of the extracellular polymeric substance (EPS) matrix of bio-films is composed of one or more of extracellular polysaccharides, DNA and proteins (Flemming et al., 2007). Channels in the biofilm allow for water, air and nutrients to get to all parts of the structure (Zhang et al., 1998). Exopolysaccharides are high molecular weight polymers of sugar synthesized extra cellularly or intra cellularly and secreted into the outside environment (Nwodo et al., 2012).

In electron microscopy, they look like linear or branched long strands that are attached to cell surfaces and help to adhere with other carbohydrates, proteins, nucleic acids and lipids (Rabin et al., 2015).
Extracellular proteins are another major EPS matrix component (FrØlund et al., 1996). Some proteins are attached to cell surfaces and polysaccharides to help with biofilm formation and stabilization. For example, glucan binding proteins (Gbps) of Streptococcus mutans play an important role in biofilm architecture maintenance by linking bacteria and exopolysaccharides. Biofilms produced by Gbps mutants have significantly reduced height (Lynch et al., 2007). Amyloids are also insoluble fibrous proteins that play a supportive role in biofilm architecture. Overexpression of Fap amyloids in Pseudomonas spp. leads to increased biofilm formation (Dueholm et al., 2013).

Extracellular DNAs (eDNAs) play an important role in biofilms formation. eDNA also helps to get attached bacterial cells to substratum surface by receptor mediated interaction (Das et al., 2010). eDNA also coordinates the twitching motility of Pseudomonas aeruginosa leads to biofilm formation (Gloag et al., 2013). Due to its negative charge, eDNA is able to chelate metal cations and some positively charged antibiotics leading to antimicrobial resistance in biofilm bacteria (Lewenza, 2013).

\section{Process of biofilm formation}

Formation of a biofilm begins with the attachment of free floating microorganisms to a stable surface. The microorganisms adhere to surface through weak van der Waals forces and hydrophobic effects (Briandet et al., 2001; Takahashi et al., 2010). Biofilm formation can be described in three stages: attachment, maturation and dispersion. The attachment step could be further categorized as a two-stage process: initial reversible attachment and irreversible attachment. The irreversibly attached biofilm can tolerate stronger physical or chemical shear forces (Renner and Weibel, 2011). In the initial 
attachment, flagella and type IV pili-mediated motilities play important roles. Flagella help to attach bacterial cells with surface, whereas Type IV pili-mediated twitching motilities enable attached cells to aggregate (Rabin et al., 2015). Once the attachment becomes irreversible, the biofilm begins to grow and mature. Maturation involves significant genetic upregulation results in marked difference between planktonic and sessile bacteria (Sauer et al., 2002). Biofilm grows from a thin layer to a 'mushroom' or 'tower' shape structure. In a thick biofilm (>100 layers), bacteria are arranged according to their metabolism and aerotolerance, in which anaerobic bacteria prefer to live in deeper part to avoid exposure to oxygen (Rabin et al., 2015).

Once maximum thickness attained, the final stage of biofilm development occurs. This is called the dispersion stage and it involves the release of planktonic cells from the biofilm. Biofilms disperse because of several factors, such as lack of nutrients, intense competition, outgrown population, etc. Dispersal could occur in the whole biofilm or just a part of it. Several enzymes help in the dispersal process, viz., dispersin B, deoxyribonuclease etc. (Kaplan 2010; Izano et al., 2008).

\section{Biofilm producing bacteria of veterinary importance}

\section{Staphylococcus spp.}

Staphylococcus spp. cause wide array of diseases in animals including mastitis, wound infection, septic arthritis, otitis, urinary tract infection etc. Mastitis is an economically important and frequently occurring disease of dairy cows. S. aureus is the primary pathogen isolated from mastitis cases (Oliveira et al., 2007). During infection, pathogens associated with mastitis form biofilms, which facilitate their persistence in the udder leads to chronic infection (Melchior et al., 2006). Approximately one-third (37.5\%) of S. aureus and $S$. epidermidis isolates from subclinical mastitis recorded as biofilm producer (Oliveira et al., 2006). It is also recorded that $S$. aureus associated with milk are more likely to produce biofilms, when compared to $S$. aureus extra-mammary sources (Haveri et al., 2008) Several genes have been associated with biofilm formation by staphylococci. These genes encode the accessory gene regulator $a g r$, icaADBC which encodes the PIA/PNAG producing enzyme and transporter, and the biofilm-associated protein Bap (Melchior et al., 2009).

Biofilm producing staphylococci plays a significant role in wound infection by impairing the healing of wounds leading to chronic infection and increase the chance of secondary bacterial infection. Moreover it also minimizes the treatment options showing high resistance to commonly used systemic and topical antibiotics. The first evidence of wound infection by biofilm bacteria comes in 1996, where $S$. aureus was inoculated onto a wound in a mouse skin and only within 6 hours biofilm was developed (Akiyama et al., 1996). Methicillin-resistant S. aureus (MRSA) could also form dense biofilm within the inoculation of 24 hours tested in murine wounds model (Roche et al., 2012). Moreira et al., (2012) demonstrated S. intermedius and $S$. simulans biofilm infection from canine otitis. Association of staphylococcal biofilm and septic arthritis is well established in experimental animal model (Colavite and Sartori, 2014).

\section{Pseudomonas aeruginosa}

$P$. aeruginosa is considered as the most potent member of multidrug-resistant (MDR) and extremely resistant (XDR) gram-negative pathogens ('ESCAPE' group) emerged throughout the world with the property to 
'escape' the treatment with antibiotics. Biofilm formation is a significant virulence property of $P$. aeruginosa generating not only antibiotic resistance, but also it acts as a constant source of infection in the host and it can prevent host defence such as chemotaxis of polynuclear immune cells. In animals, Pseudomonas aeruginosa is associated with wound infection in majority of species; respiratory infection, mastitis, enteritis in cattle; pneumonia, mastitis, fleece rot in sheep; embryonic death in poultry; and otitis, urinary tract infection in companion animals (Samanta 2013). In India, Rashid et al., (2000) could detect $P$. aeruginosa biofilms on a murine burn. Schaber et al., (2007) also demonstrated $P$. aeruginosa biofilm in a thermally injured mouse model. Seth et al., (2012) could demonstrate $P$. aeruginosa biofilm in dermal punch wounds of white rabbit ears where, they found delayed healing compared to uninfected wounds. Synergistic effect of MRSA and $P$. aeruginosa biofilm in delaying reepithelialisation of experimental porcine wound is well documented (Pastar et al., 2013).

\section{Escherichia coli}

E. coli are frequently used as indicator bacteria to monitor the trends in antimicrobial resistance because they are the most prevalent commensal enteric bacteria in humans and animals, can be cultured easily and inexpensively (Van Den Bogaard et al., 2000) and they can acquire and preserve antimicrobial resistance genes from other organisms in the environment and in animal populations (Murray 1997). E. coli are also considered as a good indicator of the selective pressure imposed by antimicrobial use in food animals (Talukdar et al., 2013) and the situation is worsened if they are capable to produce biofilm. It has been observed that established $E$. coli biofilms were difficult to treat with some antibiotics, which was supported by observations made in clinical cases involving pig, cattle and poultry (Olson et al., 2002). Some strains of enterohaemorrhagic E. coli O157: H7, a worldwide food borne pathogen, are able to form biofilms. A genome-wide transposon mutagenesis of E. coli O157: $\mathrm{H} 7$ strain EDL933 revealed that virulence plasmid pO157 plays an essential role during biofilm formation (Puttamreddy et al., 2010). Other studies indicated that the biofilm negative strains of E. coli O157: H7 can also be associated with pre-established biofilms generated by commensal E. coli strains (Uhlich et al., 2010). Nandanwar et al., (2014) isolated extraintestinal pathogenic $E$. coli (ExPEC) isolated from human and birds and were characterized in vitro using adhesin, invasin, biofilm formation and serum bactericidal assays. All the isolates were found to be equally capable of adhering to and invading the mammalian kidney cell lines. Similarly, the isolates were also able to form strong biofilms in M63 medium. Furthermore, they were recorded as resistant to the bactericidal activity of human and avian serum. Oliveira et al., (2014) demonstrated biofilm producing uropathogenic $E$. coli isolated from urinary tract infection of dog which were resistant against fluoroquinolone group of antibiotics.

\section{Other animal pathogens}

Biofilms of Listeria monocytogenes are of particular concern as they are recorded more resistance to disinfectants and sanitizing agents than planktonic cells. Many disinfectants, including quaternary ammonium compounds and hypochloride do not effectively kill the biofilms of $L$. monocytogenes (Amalaradjou et al., 2009). In New York State, biofilms of milking equipments of a dairy farm have been implicated as a potential source of bulk tank milk contamination with L. monocytogenes 
(Latorre et al., 2010). L. monocytogenes strains comprising $1 / 2 \mathrm{a}, 1 / 2 \mathrm{~b}$ and $4 \mathrm{~b}$ serotypes from clinical and food sources were studied for their capability to produce biofilm. The microtiter plate assay revealed $63.26 \%$ strains as weak, $27.55 \%$ strains as moderate and $9.18 \%$ strains as strong biofilm producer. No firm correlation was noticed between any serotype and respective biofilm formation ability (Doijad et al., 2015).

Streptococcus spp. isolated from mastitis could able to form biofilm and also possess multiple virulence genes influences the course of disease and treatment (Kaczorek et al., 2017). Biofilm forming capability of Salmonella spp. and Yersinia enterocolitica also demonstrated from food of animal origin including meat, white raw sausage, smoked meat and cheeses (Zadernowska and Chajęcka-Wierzchowska, 2017). Nair et al., (2015) demonstrated the Salmonella isolates $(85 \%)$ from food, poultry and environment with biofilm producing ability.

Biofilm formation has also been observed in Mycobacterium bovis strain BCG and Mycobacterium tuberculosis (Ojha et al., 2008). Lymphadenitis isolate of Corynebacterium pseudotuberculosis and pyelonephritis isolate of Corynebacterium renale required the addition of fetal bovine serum and incubation under $10 \% \mathrm{CO}_{2}$ for biofilm production (Olson et al., 2002).

Clostridium perfringens could produce biofilms under static conditions with an anaerobic atmosphere for a period of up to 5 days (Varga et al., 2008). Other notable studies established biofilm production capabilities of Pasteurella multocida, Brucella melitensis and Actinobacillus pleuropneumoniae from various clinical specimens of animal origin (Emery et al., 20174; Uzureau et al., 2007; Labrie et al., 2010).

\section{Biofilm and zoonoses}

Biofilm formation usually occurs in both natural and man-made environments. Biofilm forming microorganisms are frequently cause infection in human and animal and can be transmitted from each other. Biofilm forming bacteria in oral cavity of dogs can transmit infection to human through bites (Zambori et al., 2013). Similarly, biofilms formed in water tank, drinker and farm equipments can be transmit easily to the farm animal as well as animal handlers and workers. P. aeruginosa, Acinetobactor baumannii, Staphylococcus aureus are the notable examples, which can cause wound infection and implanted device related infection in man and animal (Percival 2011; Abrahamian and Goldstein, 2011). Mycobacterium avium and Mycobacterium intracellulare are also potentially zoonotic and can form biofilm in drinking water system (Percival, 2011).

\section{Biofilm and antibiotic resistance}

Bacteria in a biofilm are more resistant to antibiotics than planktonic bacteria. It has been estimated that biofilm cells can be up to 10,000 times more resistant to antibiotics than planktonic cells (Nickel et al., 1985; Costerton et al., 1995). It is highly probable that multiple factors work together to protect biofilm cells from antibiotic treatment. The exopolysaccharide matrix (EPS) prevents the penetration of antibiotic inside the biofilm. Charged polysaccharides and eDNA of the matrix can trap several kinds of antibiotics (Rabin et al., 2015). Due to slow growth rate there is limited availability of oxygen and nutrients inside biofilms, so biofilm cells, especially those in the deep layers. These features make biofilm bacteria insensitive to antibiotic that target dividing cells. For example, the targets of $\beta$-lactams are dividing cells, so when they are used on E. coli biofilms, their bacteriolytic activity is 
diminished (Ashby et al., 1994). In biofilms, there is a small subpopulation of cells called persister cells (Keren et al., 2004; Lewis 2007). Their growth rate is zero or extremely slow. Most of the antibiotics acts at this stage of microbial cell growth or division are not effective against persister cells. Efflux pumps are another important factor, which allow bacterial cells to pump intracellular toxins out, including antibiotic drugs. Efflux pumps are also expressed in planktonic cells, but some efflux pump genes are upregulated in biofilm, indicating that they contribute to antibiotic resistance (Zhang and Mah, 2008).

Plasmid borne antibiotic resistance could also be possible in single-species or multi-species biofilm by horizontal gene transfer. In biofilms, the frequencies of horizontal plasmid transfer are much higher than between planktonic cells. Studies on $S$. aureus biofilms showed that biofilms promote the spread of plasmid-borne antibiotic resistance genes by conjugation/mobilization (Savage et al., 2013).

\section{Diagnostic approaches of biofilm infection}

For achieving accurate diagnosis of biofilm associated infection bacterial culture remained as 'gold standard' of clinical microbiology for identification of pathogen is not sufficient (Hall-Stoodley et al., 2012). Aggregation of bacteria (biofilm) to specific tissue of host often give negative culture result and false positive culture result is obtained due to free floating planktonic microbes (Abdullahi et al., 2015).

The new generation molecular approaches have good reproducibility including $16 \mathrm{~S}$ rRNA polymerase chain reaction, loopmediated isothermal amplification (LAMP), fluorescence in situ hybridization (FISH) and confocal laser scanning microscopy (CLSM) (Wu et al., 2014; Abdullahi et al., 2015).

\section{Therapeutic approaches of biofilm infection}

As the biofilm producing bacteria are badly resistant to antimicrobial agent, incorporation of antibiofilm agents with conventional antibiotics are the need of the hour for effective control of biofilm associated infection. Till date, most of the published literatures were reported the following approaches in therapy against biofilm producing bacteria.

Altering the surface properties of implanted devices can minimize biofilm associated infections (Pavithra and Doble, 2008). Generally, antibiotics, heavy metal silver or silicon or their combination are used as bactericidal or bacteriostatic agents for surface coating of indwelling devices (Chen et al., 2013). Anti-adhesion surface of implanted devices also helps to reduce the attachment of pathogenic bacteria leading to significantly decreased in biofilm formation. For example, coating with poly ethylene glycol to the titanium surface markedly reduces $S$. aureus adhesion (Harris et al., 2004).

Bacteriophage therapy is a robust technique to control bacterial infections especially the multi-drug resistant bacteria. The mechanism through which phage achieves its antibiofilm action is by enzyme production, which hydrolyses and degrades the extracellular matrix of biofilm (Fu et al., 2010; Verma et al., 2010). Bacteriophages alone or combined with antibiotics might give fruitful result to check the biofilm infection.

Combined use of electric current and antibiotics greatly enhances the antimicrobial activity against biofilm (Abdullahi et al., 2015). Low frequency electric current can enhances the efficacy of polyionic antibiotics, viz., gentamicin has improved activity against 
S. epidermidis (Kasimanickam et al., 2013). Synergistic effect of low frequency ultrasound and antibiotics can effectively increase the antimicrobial action by releasing the antibiotic in a triggered manner, enhances the cell membrane permeability leading to disruption of biofilms (Kasimanickam et al., 2013). Dual action of LASER and antibacterial agents can enhances the killing properties by better penetration inside the biofilm. For example, helium/neon laser light in presence of toluidine blue killed 95\% bacteria in oral polymicrobial biofilm (Soukos and Goodson, 2011). Combination of antimicrobial drugs with nano carrier can kill the biofilm bacteria by prolonging the action of active molecules of drugs and increasing solubility and bioavailability (Kasimanickam et al., 2013).

Emergence of multidrug resistance bacteria is global public health concern. Situations may be further worsened when MDR bacteria also produce biofilms. Present scenario of biofilm associated infection in Veterinary medicine becoming a serious challenge leading to serious health hazard and economic loss. Control of indiscriminate use of antibiotics and maintaining proper biosecurity and biosafety measures might reduce the biofilm infection. In the 'post antibiotic era' the alternative therapeutic and managemental strategies should be ventured to combat the biofilm producing MDR bacterial pathogens.

\section{References}

Abdullahi, U.F., Naim, R., ALiyu, S., Mu'azu, A., Wan- Taib, W.R., Saleh, A and Baig, A.A. 2015. Loop-mediated isothermal amplification (LAMP), an innovation in gene amplification: Bridging the gap in molecular diagnostics; a review. Indian J. Sci. Technol. 9(12): 55767.

Abrahamian, F.M and Goldstein, E.J. 2011.
Microbiology of animal bite wound infections. Clin. Microbiol. Rev. 24(2): 231-246.

Akiyama, H., Kanzaki, H., Tada, J. and Arata, J. 1996. Staphylococcus aureus infection on cut wounds in the mouse skin: experimental staphylococcal botryomycosis. J. Dermatol. Sci. 11(3): 234-238.

Amalaradjou, M.A., Norris, C.E. and Venkitanarayanan, K. 2009. Effect of octenidine hydrochloride on planktonic cells and biofilms of Listeria monocytogenes. Appl. Environ. Microbiol. 75: 4089-4092.

Ashby, M.J., Neale, J.E., Knott, S.J and Critchley, I.A. 1994. Effect of antibiotics on non-growing planktonic cells and biofilms of Escherichia coli. J. Antimicrob. Chemother. 33(3): 443452.

Böhme, A., Risse-Buhl, U. and Küsel, K. 2009. Protists with different feeding modes change biofilm morphology. FEMS Microbial. Ecol. 69(2): 158-169.

Briandet, R., Herry, J.M. and BellonFontaine, M.N. 2001 Determination of the van der Waals, electron donor and electron acceptor surface tension components of static gram-positive microbial biofilms. Colloids Surf. B Biointerfaces 21(4): 299-310.

Chen, M., Yu, Q. and Sun, H. 2013. Novel strategies for the prevention and treatment of biofilm related infections. Int. J. Mol. Sci. 14(9): 18488-18501.

Clutterbuck, A.L., Woods, E.J., Knottenbelt, D.C., Clegg, P.D., Cochrane, C.A. and Percival, S.L. 2007. Biofilms and their relevance to veterinary medicine. Vet. Microbial. 121(1-2): 1-17.

Colavite, P.M. and Sartori, A. 2014. Septic arthritis: immunopathogenesis, experimental models and therapy. J. Venom Anim. Toxins Incl. Trop. Dis. 20(1): 19. 
Costerton, J.W., Lewandowski, Z., Caldwell, D.E., Korber, D.R. and Lappin-Scott, H.M. 1995. Microbial Biofilms. Annu. Rev. Microbiol. 49(1): 711-745.

Das, T., Sharma, P.K., Busscher, H.J., Vander-Mei, H.C. and Krom, B.P. 2010. Role of extracellular DNA in initial bacterial adhesion and surface aggregation. Appl. Environ. Microbiol 76(10): 3405-3408.

Doijad, S.P., Barbuddhe, S.B., Garg, S., Poahrkar, K.V. and Chakraborty, T. 2015. Biofilm-forming abilities of Listeria monocytogenes serotypes isolated from different sources. PloS One 10(9): e0137046.

Dueholm, M.S., SØndergaard, M.T. and Nilsson, M. 2013. Expression of Fap amyloids in Pseudomonas aeruginosa, $P$. fluorescens, and $P$. putida results in aggregation and increased biofilm formation. Microbiologyopen 2(3): 365-382.

Emery, B.D.D., Furian, T.Q., Pilatti, R.M., Chitolina, G.Z., Borges, K.A., Salle, C.T. and Moraes, H.L. 2017. Evaluation of the biofilm formation capacity of Pasteurella multocida strains isolated from cases of fowl cholera and swine lungs and its relationship with pathogenicity. Pesqui. Vet. Bras. 37(10): 1041-1048.

Flemming, H.C., Neu, T.R. and Wozniak, D.J. 2007. The EPS matrix: the house of biofilm cells. J. Bacteriol. 189(22): 7945-7947.

FrØlund, B., Palmgren, R., Keiding, K. and Nielsen, P.H. 1996. Extraction of extracellular polymers from activated sludge using a cation exchange resin. Water Res. 30(8): 1749-1758.

Fu, W., Forster, T., Mayer, O., Curtin, J.J., Lehman, S.M. and Donlan, R.M. 2010. Bacteriophage cocktail for the prevention of biofilm formation by Pseudomonas aeruginosa on catheters in an in vitro model system. Antimicrob. Agents. Chemother. 54(1): 397-404.

García, A.B. and Percival, S.L. 2011. Zoonotic infections: the role of biofilms. In Biofilms and Veterinary Medicine (pp. 69-110). Springer Berlin Heidelberg.

Gloag, E.S., Turnbull, L., Huang, A., Vallotton, P., Wang, H. and Monahan, L.G. 2013. Self-organization of bacterial biofilms is facilitated by extracellular DNA. Proc. Natl. Acad. Sci 110(28): 11541-11546.

Hall-Stoodley, L., Stoodley, P., Kathju, S., Høiby, N., Moser, C., William Costerton, J., Moter, A. and Bjarnsholt, T. 2012. Towards diagnostic guidelines for biofilm-associated infections. FEMS Immunol. Med. Microbiol. 65(2): 127145.

Harris, L.G., Tosatti, S., Wieland, M., Textor, M. and Richards, R.G. 2004. Staphylococcus aureus adhesion to titanium oxide surfaces coated with non-functionalized and peptidefunctionalized poly (L-lysine)-graftedpoly (ethylene glycol) copolymers. Biomaterials 25(18): 4135-4148.

Haveri, M., Hovinen, M., Roslöf, A. and Pyörälä, S. 2008 Molecular types and genetic profiles of Staphylococcus aureus strains isolated from bovine intramammary infections and extramammary sites. J. Clin. Microbiol. 46(11): 3728-3735.

Izano, E.A., Sadovskaya, I., Wang, H., Vinogradov, E., Ragunath, C., Ramasubbu, N., Jabbouri, S., Perry, M.B. and Kaplan, J.B. 2008. Poly-Nacetylglucosamine mediates biofilm formation and detergent resistance in Aggregatibacter actinomycetemcomitans. Microb. Pathog. 44(1): 52-60.

Joubert, L.M., Wolfaardt, G.M. and Botha, A. 2006. Microbial exopolymers link 
predator and prey in a model yeast biofilm system. Microb. Ecol. 52(2): 187-197.

Kaczorek, E., Małaczewska, J., Wójcik, R., Rękawek, W. and Siwicki, A.K. 2017. Phenotypic and genotypic antimicrobial susceptibility pattern of Streptococcus spp. isolated from cases of clinical mastitis in dairy cattle in Poland. J. Dairy Sci. 100(8): 6442-6453.

Kaplan, J.A. 2010. Biofilm dispersal: mechanisms, clinical implications, and potential therapeutic uses. J. Dent. Res. 89(3): 205-218.

Kasimanickam, R.K., Ranjan, A., Asokan, G.V., Kasimanickam, V.R. and Kastelic, J.P. 2013. Prevention and treatment of biofilms by hybrid- and nanotechnologies. Int. J. Nanomed. 8: 2809-2819.

Keren, I., Shah, D., Spoering, A., Kaldalu, N. and Lewis, K. 2004. Specialized persister cells and the mechanism of multidrug tolerance in Escherichia coli. J. Bacteriol. 186(24): 8172-8180.

Kokare, C.R., Chakraborty, S., Khopade, A.N. and Mahadik, K.R. 2009. Biofilm: Importance and applications. Ind. J. Biotechnol. 8: 159-168.

Labrie, J., Pelletier-Jacques, G., Deslandes, V., Ramjeet, M., Auger, E., Nash, J.H. and Jacques, M. 2010 Effects of growth conditions on biofilm formation by Actinobacillus pleuropneumoniae. Vet. Res. 41(1): 1-17.

Latorre, A.A., Van Kessel, J.S., Karns, J.S., Zurakowski, M.J., Pradhan, A.K., Boor, K.J., Jayarao, B.M., Houser, B.A., Daugherty, C.S. and Schukken, Y.H. 2010. Biofilm in milking equipment on a dairy farm as a potential source of bulk tank milk contamination with Listeria monocytogenes. J. Dairy Sci. 93: 2792-2802.

Lewenza, S. 2013. Extracellular DNAinduced antimicrobial peptide resistance mechanisms in Pseudomonas aeruginosa. Front. Microbiol. 4: 21.

Lewis, K. 2007. Persister cells, dormancy and infectious disease. Nat. Rev. Microbiol. 5(1): 48-56.

Lynch, D.J., Fountain, T.L., Mazurkiewicz, J.E. and Banas, J.A. 2007. Glucanbinding proteins are essential for shaping Streptococcus mutans biofilm architecture. FEMS Microbiol. Let.t 268(2): 158-165.

Melchior, M.B., Vaarkamp, H. and FinkGremmels, J. 2006. Biofilms: a role in recurrent mastitis infections. Vet. J. 171: 398-407.

Melchior, M.B., Van Osch, M.H.J., Graat, R.M., Van Duijkeren, E., Mevius, D.J., Nielen, M., Gaastra, W. and FinkGremmels, J. 2009. Biofilm formation and genotyping of Staphylococcus aureus bovine mastitis isolates: evidence for lack of penicillinresistance in Agr-type II strains. Vet. Microbiol. 137(1-2): 83-89.

Moreira, C.A., Oliveira, L.C.D., Mendes, M.S., Santiago, T.D.M., Barros, E.B. and Carvalho, C.B.M.D. 2012. Biofilm production by clinical Staphylococci strains from canine otitis. Braz. J. Microbiol. 43(1): 371-374.

Murray, B.E. 1997. Vancomycin-resistant enterococci. Am. J. Med. 102(3): 284293.

Nair, A., Rawool, D.B., Doijad, S., Poharkar, K., Mohan, V., Barbuddhe, S.B., Kolhe, R., Kurkure, N.V., Kumar, A., Malik, S.V. and Balasaravanan, T. 2015. Biofilm formation and genetic diversity of Salmonella isolates recovered from clinical, food, poultry and environmental sources. Infect. Gen. Evol. S1567-1348(15): 335-364.

Nandanwar, N., Janssen, T., Kühl, M., Ahmed, N., Ewers, C. and Wieler, L.H. 2014. Extraintestinal pathogenic Escherichia coli (ExPEC) of human and 
avian origin belonging to sequence type complex 95 (STC95) portray indistinguishable virulence features. Int. J. Med. Microbiol. 304(7):835-842.

Nickel, J.C., Ruseska, I., Wright, J.B. and Costerton, J.W. 1985. Tobramycin resistance of Pseudomonas aeruginosa cells growing as a biofilm on urinary catheter material. Antimicrob. Agents. Chemother. 27(4): 619-624.

Nwodo, U.U., Green, E. and Okoh, A.I. 2012. Bacterial exopolysaccharides: functionality and prospects. Int. J. Mol. Sci. 13(11): 14002-14015.

Ojha, A.K., Baughn, A.D., Sambandan, D., Hsu, T., Trivelli, X., Guerardel, Y., Alahari, A., Kremer, L., Jacobs, W.E. and Hatfull, G.F. 2008. Growth of Mycobacterium tuberculosis biofilms containing free mycolic acids and harbouring drug-tolerant bacteria. Mol. Microbiol. 69: 164-174.

Oliveira, M., Bexiga, R., Nunes, S.F., Carneiro, C., Cavaco, L.M., Bernardo, F. and Vilela, C.L. 2006. Biofilmforming ability profiling of Staphylococcus aureus and Staphylococcus epidermidis mastitis isolates. Vet. Microbiol. 118: 133-140.

Oliveira, M., Dias, F.R. and Pomba, C. 2014. Biofilm and fluoroquinolone resistance of canine Escherichia coli uropathogenic isolates. BMC Res. Notes. 7(1): 499.

Oliveira, M., Nunes, S.F., Carneiro, C., Bexiga, R., Bernardo, F. and Vilela, C.L. 2007. Time course of biofilm formation by Staphylococcus aureus and Staphylococcus epidermidis mastitis isolates. Vet. Microbiol. 124: 187-191.

Olson, M.E., Ceri, H., Morck, D.W., Buret, A.G. and Read, R.R. 2002. Biofilm bacteria: formation and comparative susceptibility to antibiotics. Can. J. Vet. Res. 66: 86-92.
Pastar, I., Nusbaum, A.G., Gil, J., Patel, S.B., Chen, J., Valdes, J., Stojadinovic, O., Plano, L.R., Tomic-Canic, M. and Davis, S.C. 2013. Interactions of methicillin resistant Staphylococcus aureus USA300 and Pseudomonas aeruginosa in polymicrobial wound infection. PloS One 8(2): e56846.

Pavithra, D. and Doble, M. 2008. Biofilm formation, bacterial adhesion and host response on polymeric implants - issues and prevention. Biomed. Mater. 3(3): 034003

Percival, S.L., Hill, K.E., Malic, S., Thomas, D.W. and Williams, D.W. 2011. Antimicrobial tolerance and the significance of persister cells in recalcitrant chronic wound biofilms. Wound Repair. Regen. 19(1): 1-9.

Percival, S.L., Malic, S., Cruz, H. and Williams, D.W. 2011. Introduction to biofilms. In Biofilms and veterinary medicine (pp. 41-68). Springer, Berlin, Heidelberg.

Puttamreddy, S., Cornick, N.A. and Minion, F.C. 2010. Genomewide transposon mutagenesis reveals a role for $p 0157$ genes in biofilm development in Escherichia coli O157:H7 EDL933. Infect. Immun. 78: 2377-2384.

Queck, S.Y., Weitere, M., Moreno, A.M., Rice, S.A. and Kjelleberg, S. 2006. The role of quorum sensing mediated developmental traits in the resistance of Serratia marcescens biofilms against protozoan grazing. Environ. Microbiol. 8: 1017-1025.

Rabin, N., Zheng, Y., Opoku-Temeng, C., Du, Y., Bonsu, E. and Sintim, H.O. 2015. Biofilm formation mechanisms and targets for developing antibiofilm agents. Future Med. Chem. 7(4): 493512.

Rashid, M.H., Rumbaugh, K., Passador, L., Davies, D.G., Hamood, A.N., Iglewski, B.H. and Kornberg, A. 2000 
Polyphosphate kinase is essential for biofilm development, quorum sensing, and virulence of Pseudomonas aeruginosa. Proc. Nat. Acad. Sci. 97(17): 9636-9641.

Rasmussen, T.B. and Givskov, M. (2006) Quorum-sensing inhibitors as antipathogenic drugs. Int. J. Med. Microbiol. 296(23):149-161.

Renner, L.D. and Weibel, D.B. 2011. Physicochemical regulation of biofilm formation. MRS Bull. 36(5): 347-355.

Roche, E.D., Renick, P.J., Tetens, S.P. and Carson, D.L. 2012. A model for evaluating topical antimicrobial efficacy against methicillin-resistant

Staphylococcus aureus biofilms in superficial murine wounds. Antimicrob. Agents. Chemother. 56(8): 4508-4510.

Samanta, I. Pseudomonas and Burkholderia. In: Veterinary bacteriology, New India Publishing Agency, New Delhi, India: 2013. P. 209-223.

Sauer, K., Camper, A.K., Ehrlich, G.D., Costerton, J.W. and Davies, D.G. 2002. Pseudomonas aeruginosa displays multiple phenotypes during development as a biofilm. J. Bacteriol. 184(4): 1140-1154.

Savage, V.J., Chopra, I. and O'Neill, A.J. 2013. Staphylococcus aureus biofilms promote horizontal transfer of antibiotic resistance. Antimicrob. Agents. Chemother. 57(4): 1968-1970.

Schaber, J.A., Triffo, W.J., Suh, S.J., Oliver, J.W., Hastert, M.C., Griswold, J.A., Auer, M., Hamood, A.N. and Rumbaugh, K.P. 2007. Pseudomonas aeruginosa forms biofilms in acute infection independent of cell-to-cell signaling. Infect. Immun. 75(8): 37153721.

Seth. A.K., Geringer, M.R., Gurjala, A.N., Hong, S.J., Galiano, R.D., Leung, K.P. and Mustoe T.A. 2012. Treatment of Pseudomonas aeruginosa biofilm- infected wounds with clinical wound care strategies: a quantitative study using an in vivo rabbit ear model. Plast. Reconstr. Surg. 129(2): 262e-274e.

Soukos, N.S. and Goodson, J.M. 2011. Photodynamic therapy in the control of oral biofilms. Periodontol. 2000 55(1): 143-166.

Takahashi, H., Suda, T., Tanaka, Y. and Kimura, B. 2010. Cellular hydrophobicity of Listaria monocytogenes involves initial attachment and biofilm formation on the surface of polyvinyl chloride. Lett. Appl. Microbiol. 50(6): 618-625.

Talukdar, P.K., Rahman, M., Rahman, M., Nabi, A., Islam, Z., Hoque, M.M., Endtz, H.P. and Islam, M.A. 2013. Antimicrobial resistance, virulence factors and genetic diversity of Escherichia coli isolates from household water supply in Dhaka, Bangladesh. Plos One 8(4): e61090.

Taylor, E.N. and Webster, T.J. 2009. The use of superparamagnetic nanoparticles for prosthetic biofilm prevention. Int. J. Nanomed. 4: 145.

Uhlich, G.A., Rogers, D.P. and Mosier, D.A. 2010. Escherichia coli serotype O157: $\mathrm{H} 7$ retention on solid surfaces and peroxide resistance is enhanced by dualstrain biofilm formation. Foodborne Patho. Dis. 7: 935-943.

Uzureau, S., Godefroid, M., Deschamps, C., Lemaire, J., De Bolle, X. and Letesson, J.J. 2007. Mutations of the quorum sensing-dependent regulator VjbR lead to drastic surface modifications in Brucella meletensis. J. Bacteriol. 189(16): 6035-6047.

Van den Bogaard, A.E.J.M., London, N., and Stobberingh, E.E. (2000) Antimicrobial resistance in pig faecal samples from The Netherlands (five abattoirs) and Sweden. J. Antimicrob. Chemother. 45(5): 663-671. 
Varga, J.J., Therit, B., and Melville, S.B. 2008. Type IV pili and the CcpA protein are needed for maximal biofilm formation by the gram-positive anaerobic pathogen Clostridium perfringens. Infect. Immune. 46(11): 4944-4951.

Verma, V., Harjai, K. and Chhibber, S. 2010. Structural changes induced by a lytic bacteriophage make ciprofloxacin effective against older biofilm of Klebsiella pneumoniae. Biofouling 26(6): 729-737.

Wu, H., Moser, C., Wang, H.Z., Høiby, N. and Song, Z.J. 2015. Strategies for combating bacterial biofilm infections. Int. J. Oral. Sci. 7(1): 1.

Zadernowska, A. and ChajęckaWierzchowska, W. 2017. Prevalence, biofilm formation and virulence markers of Salmonella sp. and Yersinia enterocolitica in food of animal origin in Poland. LWT Food Sci. Technol. 75: 552-556.

Zambori, C., Cumpanasoiu, C., Mladin, B. and Tirziu, E. 2013. Biofilms in oral cavity of dogs and implication in zoonotic infections. Scientific Papers Anim. Sci. Biotechnol. 46(1): 155-158.

Zhang, L. and Mah, T.F. 2008. Involvement of a novel efflux system in biofilmspecific resistance to antibiotics. J. Bacteriol. 190(13): 4447-4452.

Zhang, X., Bishop, P.L. and Kupferle, M.J. 1998 Measurement of polysaccharides and proteins in biofilm extracellular polymers. Water Sci. Technol. 37 (45): 345-348.

\section{How to cite this article:}

Chakraborty, S., T.K. Dutta, A.De, M. Das and Ghosh, S. 2018. Impact of Bacterial Biofilm in Veterinary Medicine: An Overview. Int.J.Curr.Microbiol.App.Sci. 7(04): 3228-3239. doi: https://doi.org/10.20546/ijcmas.2018.704.366 